\title{
Effects of US parameters on classical conditioning of cat hindlimb flexion
}

\author{
BRETT E. POLENCHAR, ANTHONY G. ROMANO, JOSEPH E. STEINMETZ, \\ and MICHAEL M. PATTERSON \\ Ohio University, Athens, Ohio
}

\begin{abstract}
Unconditioned stimulus (US) intensity and duration were manipulated to determine their effects on cat hindlimb flexion conditioning. Seven consecutive days of acquisition training of a hindlimb flexor response to a tone conditioned stimulus (CS) were followed by 2 days of extinction. Eight animals in each of 12 groups received a 1-, 2-, 3-, or 4-mA, 60-Hz shock delivered to the right hindleg for 25, 50, or $100 \mathrm{msec}$ as the US. Analysis of conditioned-response (CR) frequency indicated that conditioned responding was a positive function of both the intensity and duration of shock, although these variables did not interact with one another. CR latency and amplitude were decreased and increased, respectively, by increases in US intensity. The pattern of results reported here may support a contiguity notion of conditioning, and are discussed in the context of other conditioning preparations.
\end{abstract}

The classically conditioned nictitating membrane (NM) response in the rabbit has become a useful tool for investigating the neurophysiological basis of learning (e.g., Thompson, 1983). Another subject favored for neuroanatomical and electrophysiological work is the cat. However, because conditioning behavior is not as well defined for the cat as for the rabbit, similar neurobiological work on learning has not developed. For example, classical conditioning of the cat hindlimb flexor response has produced disagreement about the stimulus characteristics necessary for optimal conditioning (Bruner, 1969; O'Brien \& Packham, 1973).

Recently, Romano, Steinmetz, and Patterson (1980) described an apparatus and the methodology for restraining the cat for classically conditioning the nictitating membrane (NM) response without long periods of adaptation or awkward treatment of the animal. The restraint system has been successfully employed in classically conditioning the cat NM response (Patterson, Olah, \& Clement, 1977) and in correlating hippocampal neural activity with the acquisition of the conditioned NM response (Patterson, Berger, \& Thompson, 1979). With some modification of the restraint system, the legs can be made to hang free to permit hindlimb flexion conditioning.

A preliminary report on this work was presented at the 10th annual meeting of The Society for Neuroscience in November 1980. Portions of this work were supported by the American Osteopathic Association Bureau of Research, Grant 81-08-023, and funds from the Ohio University College of Osteopathic Medicine. B. E. Polenchar, A. G. Romano, and J. E. Steinmetz are in the Department of Psychology of Ohio University. M. M. Patterson's mailing address is: College of Osteopathic Medicine, Ohio University, Athens, Ohio 45701.
In a separate study, we have shown that with this system the hindlimb response shows rapid, stable conditioning that is relatively free of nonassociative responses and is well tolerated by the animal (Patterson \& Romano, 1979). Our purpose in the present investigation was to examine conditioned performance of this response as a function of both unconditioned stimulus (US) intensity and duration.

\section{METHOD}

\section{Subjects}

Ninety-six mongrel cats were used as subjects. The animals were housed either separately or in pairs and maintained on a 12-h lightdark cycle, with food and water available ad lib.

\section{Apparatus}

The apparatus used to classically condition the cat's hindlimb flexion response is described in detail elsewhere (Romano et al., 1980). Briefly, each cat was placed in an elevated Plexiglas restraining device in which the front legs were tucked underneath the animal in a normal resting position and the hindlegs were allowed to hang free. The posterior surface of the lower right hindleg was shaved, and two stainless steel Autoclip sutures were affixed to the skin for delivery of the US. The sutures were placed just above the ankle $2 \mathrm{~cm}$ apart. A third suture was placed slightly higher to allow the leg to be mechanically coupled to the arm of a Minitorque potentiometer via a hook and elastic cord.

The animals were conditioned inside converted, ventilated refrigerator shells. Illumination inside the shells was provided by a 40-W houselight located on the ceiling. Two speakers mounted on the ceiling of the chamber directly over the animals' heads provided a continuous $65-\mathrm{dB}$ white masking noise and the tone conditioned stimulus.

For groups that were run earlier in our study, stimuli were delivered by preprogrammed Coulbourn solid-state equipment. Leg movements were transduced to dc signals and recorded on a polygraph for later analysis. For other groups, an Apple II+/FIRST microprocessor system (Scandrett \& Gormezano, 1980) was used to control stimuli and collect leg-movement data on-line. However, the timing of stimuli and accuracy of the collected data was 
the same with both types of equipment (see Marshall-Goodell, Schreurs, \& Gormezano, 1982).

\section{Procedure}

The animals were divided into 12 different US groups of eight animals each. The US for each group was a 1-, 2-, 3-, or 4-mA, $60-\mathrm{Hz}$ shock delivered to the right hindleg for 25,50 , or $100 \mathrm{msec}$. For all groups, the CS was a $77-\mathrm{dB}, 1-\mathrm{kHz}$ tone that overlapped and coterminated with the US. The CS-US interval was $300 \mathrm{msec}$. The intertrial interval (ITI) was 50,60 , or $70 \mathrm{sec}$ and averaged $60 \mathrm{sec}$ in length. On each day of acquisition, each animal was given 45 conditioning trials (CS-US) and six CS-alone test trials, one before and after each block of nine paired trials. Four animals in a control group were exposed to unpaired presentations of the tone and 4-mA, 100-msec shock, with an average interval of $30 \mathrm{sec}$ between stimuli.

One day of adaptation to the experimental situation was given to all the animals. This included placing an animal in the restraint and, after attaching the recording and stimulating devices, placing it in the refrigerator shell for the duration of a daily acquisition session. Acquisition training began on the day following adaptation and continued for 7 consecutive days. This was followed by 2 days of extinction training. During extinction trials, only the CS was presented; the other training parameters, i.e., ITI and CS duration for each of the respective groups, remained the same. The control animals experienced the same extinction training protocol.

During acquisition and extinction, a $C R$ was defined as a right hindleg flexion greater than $.5 \mathrm{~mm}$ within the 300 -msec period immediately following CS onset. Trials on which the animal showed criterion movement in a 200 -msec pre-CS baseline period were completed, but the response data were not included in further analyses. Conditioned response latency and response amplitude in millimeters of hindlimb movement at the peak of the response, were also recorded.

\section{RESULTS}

The control group's level of performance (Figure 1) reached a peak of $16 \%$ responding on Day 2 and generally declined thereafter. Daily mean response levels shown in Figure 1 were uncharacteristic of most of the control animals' performances,

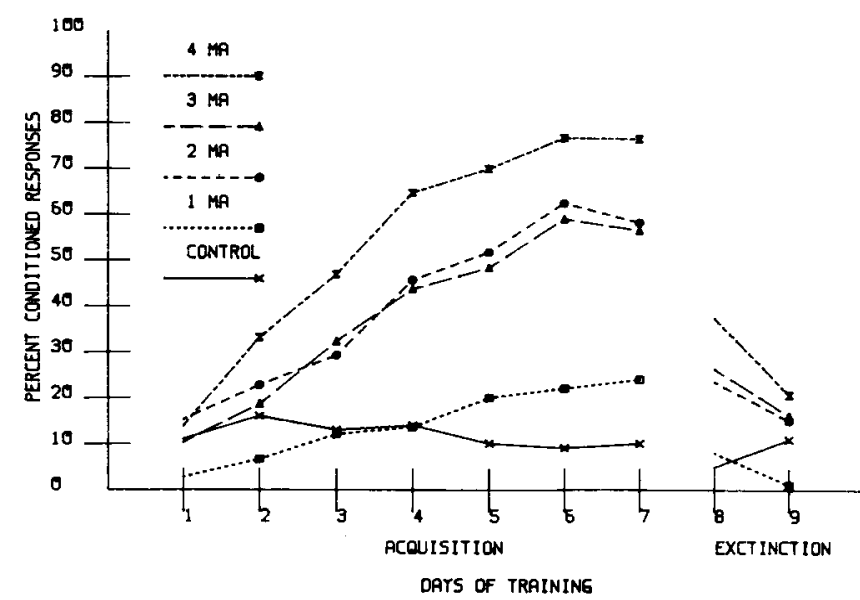

Figure 1. Daily mean CR levels for US intensity groups in acquisition and extinction. and were largely due to a single subject's continued high rate of responding. Neither unpaired-stimulus training $[F(6,18)=.49, \mathrm{n} . \mathrm{s}$.] nor extinction training $[\mathrm{t}(3)=.94, \mathrm{n} . \mathrm{s}$.$] produced reliable changes in control$ animals' responses to the tone CS.

Analysis of between-session responding for the experimental groups showed that during acquisition, responding increased reliably for all groups $[F(2,83)$ $=76.19, \mathrm{p}<.001]$. US intensity produced an increasing trend in the overall response means (Sheffé's test, $\mathrm{p}<.01$ ). Intensity groups also differed in their rate of $C R$ acquisition $[F(18,498)=3.12, p<.001]$. $A$ breakdown of the intensity $\times$ sessions interaction (shown in Figure 1) revealed significant differences: beginning on Day 3, between the 4- and 1-mA groups (p < .05); on Days 4 and 5, between the 4- and 1-mA (p $<.01)$ and 2- and 1-mA groups ( $<<.05)$; and on Days 6 and 7, between the $1-\mathrm{mA}$ and 2-, 3-, and 4$\mathrm{mA}$ groups $(\mathrm{p}<.01$ for all comparisons).

US duration, although it did not interact with intensity, produced similar results in overall $C R$ performance, supporting a linearly increasing trend in the overall response means (Sheffé's test, $p<.05$ ). Duration also interacted with between-session performance $[F(12,498)=2.15, p<.05$, see Figure 2]. However, the effect primarily reflected the betweensession response increases for each of the groups. No significant differences existed among the three duration conditions on any single day of training.

Response amplitude data were taken from CSalone test trials so that CRs unaffected by the animal's response to shock could be examined. Overall, CR amplitudes increased throughout training for the experimental groups $[F(6,498)=35.43, p<.001]$. US intensity supported both overall $[F(3,83)=4.97$, $\mathrm{p}<.01]$ and rate-of-growth $[F(18,498)=5.76, p<$ .01] differences between groups. Increasing US intensity produced a linearly increasing trend in the overall mean amplitudes (Sheffé's test, $p<.01$ ). Further analysis of the intensity $\times$ sessions interaction (Figure 3) revealed that amplitude differences first appeared on Day 4 between the 4- and 1-mA groups $(p<.01)$ and then on Days 5 through 7 between the 1-mA group and the 3- and 4-mA groups $(p<.01)$. Changes in US duration did not produce significant overall or between-session differences in CR amplitude.

Changes in US intensity supported a decreasing trend in $C R$ onset latency $[F(3,83)=2.86, p<.05]$. However, the intensity $\times$ sessions interaction was not significant. Changes in US duration did not produce significant differences in CR onset latency or interact with intensity or the repeated measure. Analysis of the repeated measure showed that the decrease in $C R$ latency across sessions was significant $[F(6,498)$ $=2.83, \mathrm{p}<.01]$.

Figures 1, 2, and 3 also show the effects of US intensity and duration on CR frequency and amplitude 


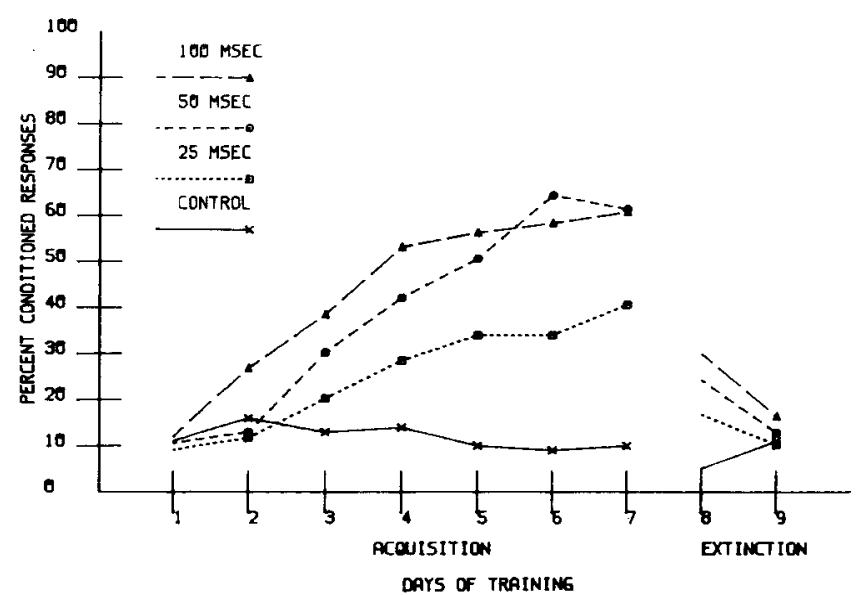

Figure 2. Daily mean CR levels for US duration groups in acquisition and extinction.

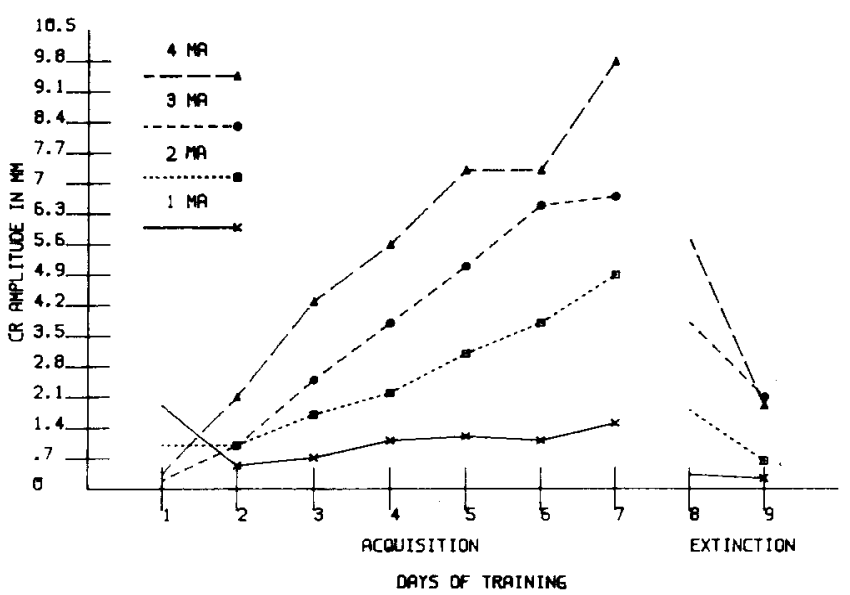

Figure 3. Daily mean response amplitudes for US intensity groups in acquisition and extinction.

during extinction. Decreasing trends in both response measures are apparent; only US intensity yielded reliable differences in overall $C R$ frequency $[F(3,83)$ $=7.24, \mathrm{p}<.001$, Figure 1$]$ and $C R$ amplitude $[F(3,83)$ $=7.64, p<.01$, Figure 3] during extinction.

\section{DISCUSSION}

We have been able to demonstrate that cat hindlimb flexion can be brought under reliable Pavlovian control using a delayed conditioning paradigm with shock US. As a control for the effects of sensitization, we exposed four animals to unpaired presentations of the CS and 4-mA, 100-msec shock. The results of this group suggest that sensitization in the cat hindlimb preparation is minimal, similar to that of rabbit NM conditioning (Gormezano, Schneiderman, Deaux, \& Fuentes, 1962). Parametric manipulation of the shock US in paired-stimulus conditioning groups yielded the following results. (1) The rate of $C R$ acquisition and overall $C R$ frequency was a positive function of US intensity. (2) Increasing US duration also produced a higher overall level of responding; however, it did not affect the rate of conditioning. (3) Increasing US intensity increased the amplitude and decreased the onset latency of CRs, but US duration had no effect on these characteristics.

The effects of US intensity in the present experiment are consistent with data from previous cat hindlimb (Bruner, 1969) and other conditioning preparations, including rabbit NM (Ashton, Bitgood, \& Moore, 1969; Smith, 1968), cat heart rate (Bruner, 1969), and human eyeblink conditioning (Prokasy \& Harsanyi, 1968). In general, CR frequency bears a direct positive relationship to US intensity. For example, Smith (1968) reported that animals presented with 1,2 , or 4-mA, 50-msec shock showed increased $C R$ acquisition, increases in $C R$ amplitude, and decreases in CR latency related to increasing US intensity. Similarly, we found that increases in US intensity led to increases in the rate and overall level of conditioning, the amplitude of the conditioned response, and, to a lesser degree, to decreases in response latency (i.e., latency differences occurred only with extreme intensity differences). Likewise, Ashton et al. (1969) reported that CR frequency was a positive function of US intensity over a similar range of intensities, including $.5,2$, and $4 \mathrm{~mA}$.

While the results of US intensity studies are fairly consistent, those of US duration are not. In the Ashton et al. study previously cited, US durations of $\mathbf{5 0}$ and $350 \mathrm{msec}$ had a positive effect on CR acquisition to $\mathrm{CS}+$ but not to CS - . However, other investigations of the rabbit NM response have revealed CR frequency functions that are either concave down (Frey \& Butler, 1973) or inverse (Tait, Kehoe, \& Gormezano, 1983). Frey and Butler found that a 100 -msec shock US produced a higher asymptotic level of responding than either a 50- or 200-msec stimulus. Tait et al., using substantially longer duration shock, found that CR frequency was inversely related to US duration over a range of durations, including 50, 1,500, and $6,000 \mathrm{msec}$. However, it is likely that the use of extremely long-duration shock produced decrements in performance due to fatigue or overarousal. Tait et al. reported that decrements in responding occurred within individual sessions, suggesting signs of fatigue.

Theoretically, the effects of US intensity and duration may give a clue as to the reinforcing properties of the US. There are two major hypotheses, contiguity and effect, although other more recent formulations exist (see Tait et al., 1983). In brief, models of conditioning based on a law of effect (Thorndike, 1913) assert that there must be a motivational component to US presentation, while contiguity theorists (Sheffield, 1965) argue that the US-UR complex is 
the sufficient condition for learning. The motivational nature of the US in classical conditioning was formulated by Hull (1943), who proposed that a state of "drive reduction" occurred at the point of US termination. Hull's hypothesis predicted that when US termination was delayed past some optimal point (probably at the peak of the UR), the association between CS and CR would be decreased. According to Frey and Butler (1973), the superiority of their 100 -msec group appeared because US termination occurred at this optimal point. Their 50-msec stimulus terminated at UR onset, too quickly for drive reduction to occur, and the 200 -msec stimulus carried US termination past the point of normal UR cessation.

While these results seem to support an effect formulation of conditioning, those of Ashton et al. (1969) and possibly Tait et al. (1983) support a contiguity notion of conditioning. According to contiguity theory (Sheffield, 1965), the CS-CR association is dependent on the ability of the US to reliably evoke the UR in the proximity of the CS. Anything that serves to increase the vigor of the UR will increase the likelihood of conditioned responding. Therefore, contiguity theory would predict that increases in US intensity or duration would serve to ensure the occurrence of a strong $U R$ and increase the degree of association between CS and CR. A number of studies already cited agree that $C R$ frequency is a positive function of US intensity. With regard to duration, the Ashton et al. results demonstrate that increases in US duration produce better conditioning. The Tait et al. results may also be consistent with contiguity theory. Tait et al. found that when total US exposure was equated across groups by additional US presentations interpolated between trials, CR frequency became a positive function of the US paired with the CS. Our results also show a positive relationship between CR frequency and US duration; however, this relationship is not a strong one. Unlike intensity, US duration affected the level of conditioning, but did not affect the rate of conditioning or the amplitude of the conditioned response. Perhaps longer durations may increase the vigor of URs and the likelihood of conditioned responding, consistent with the expectations of contiguity theory, but not necessarily affect performance characteristics of the learned response, such as amplitude or onset latency. These characteristics would seem to be primarily determined at US onset by stimulus intensity, as evidenced by the positive relationship between US intensity and $C R$ amplitude and latency.

In summary, the cat hindlimb preparation shows rapid and stable conditioning using an ac shock US from 2 to $4 \mathrm{~mA}$ and 25 to $100 \mathrm{msec}$ in duration. Increases in these parameters produce a corresponding increase in CR frequency. Sensitization is minimal, and a significant decrease in responding is seen within 2 days of extinction training. The stability of the preparation and ease of training make it suitable for further neurophysiological work in learning, similar to the current use of the rabbit NM preparation (Thompson, 1983), inasmuch as there is a profusion of literature about the cat's neuroanatomy.

\section{REFERENCES}

Ashton, A. B., Bitgood, S. C., \& Moore, J. W. (1969). Auditory differential conditioning of the rabbit nictitating membrane response: III. Effects of US intensity and duration. Psychonomic Science, 15, 127-128.

Brune R, A. (1969). Reinforcement strength in classical conditioning of leg flexion, freezing, and heart rate in cats. Conditional Reflex, 4, 24-31.

Frey, P. W., \& Butlen, C. S. (1973). Rabbit eyelid conditioning as a function of unconditioned stimulus duration. Journal of Comparative and Physiological Psychology, 65, 289-294.

Gormezano, I., Schneiderman, N., Deaux, E. G., \& Fuentes, I. (1962). Nictitating membrane: Classical conditioning and extinction in the albino rabbit. Science, 138, 33-34.

Hull, C. L. (1943). Principles of behavior. New York: AppletonCentury-Crofts.

Marshall-Goodell, B., Schreurs, B. G., \& Gormezano, I. (1982). Ruler vs. the Apple II/FIRST system analysis of analog signals in classical conditioning. Behavior Research Methods \& Instrumentation, 14, 519-525.

O'Brien, J., \& Packham, S. (1973). Conditioned leg movement in the cat with massed trials, trace conditioning, and weak US intensity. Conditional Reflex, 8, 116-124.

Patterson, M. M., Berger, T. W., \& Thompson, R. F. (1979). Neural plasticity recorded from cat hippocampus during classical conditioning. Brain Research, 163, 339-343.

Patterson, M. M., Olah, J., \& Clement, J. (1977). Classical nictitating membrane conditioning in the awake, normal, restrained cat. Science, 196, 1124-1126.

Patterson, M. M., \& Romano, T. (1979). Classical conditioning of the hindlimb flexion reflex in the cat. Journal of the American Osteopathic Association, 78, 898-899.

Prokasy, W. F., \& Harsanyi, M. A. (1968). Two-phase model for human eyelid conditioning. Journal of Experimental Psychology, 78, 359-368.

Romano, A. G., Steinmetz, J. E., \& Pattenson, M. M. (1980). A versatile cat-restraint system. Behavior Research Methods \& Instrumentation, 12, 455-458.

SCANDRETT, J., \& Gormezano, I. (1980). Microprocessor control and A/D data acquisition in classical conditioning. Behavior Research Methods \& Instrumentation, 12, 120-125.

SHEFFIELD, F. D. (1965). Relation between classical conditioning and instrumental learning. In W. F. Prokasy (Ed.), Classical conditioning. New York: Appleton-Century-Crofts.

SMITH, M. C. (1968). CS-US interval and US intensity in classical conditioning of the rabbit's nictitating membrane response. Journal of Comparative and Physiological Psychology, 66, 679-687.

Tait, R. W., Kehoe, E. J., \& Gormezano, I. (1983). Effects of US duration on classical conditioning of the rabbit's nictitating membrane response. Journal of Experimental Psychology: Animal Behavior Processes, 9, 91-101.

Thompson, R. F. (1983). The engram found? Initial localization of the memory trace for a basic form of associative learning. In J. M. Sprague \& A. N. Epstein (Eds.), Progress in psychobiology and physiological psychology (Vol. 10). New York: Academic Press.

Thonndike, E. L. (1913). The psychology of learning. New York: Columbia University Press.

(Manuscript received March 21, 1983; revision accepted for publication September 7, 1983.) 